\title{
COMO UM GINECOLOGISTA, SE TORNOU SEXÓLOGO.
}

\author{
Entrevista com o Professor Ricardo Cavalcanti
}

Por Paulo Canella

Ricardo Cavalcanti é Medico Ginecologista. Doutor em medicina pela UFPE. Ex-presidente da Comissão Nacional de Sexologia da FEBRASGO. Fundador e ex Presidente da SBRASH Membro da FLASOG. Fundador e coordenador do Curso Intensivo de Terapia Sexual (CITS Bahia)

Esta entrevista pedida ao Professor Ricardo Cavalcanti pelo editor Paulo Roberto Bastos Canella da RBSH continha as perguntas abaixo:

Como foi que você, um ginecologista, se tornou sexólogo? Como foi isso?

Como foi que você se namorou e casou com a Psicologia?

Você foi um dos artífices da introdução da Sexologia na Ginecologia, e hoje? Como anda a Sexologia na Ginecologia?

Como você vê a pesquisa em Sexologia?

Você foi o criador do CITS lá pelos tempos em que sexualidade era tabu, ele, o CITS, continua ate hoje, o que mudou de lá para cá?

Como você vê a SBRASH no plano internacional, WAS, FLASSES, SLAM, etc.?

Como o governo pode ser assessorado pela SBRASH?

Qual o papel da SBRASH no ensino da sexualidade? Você acha que a SBRASH deveria ter um curso superior de atualização em sexualidade?

Ricardo optou por respondê-las em um texto corrido:

Eu acredito que tudo começou lá pela década de 70. Até aquela época nos consultórios de ginecologia não se falava em sexo. Havia por assim dizer uma conspiração de silêncio entre o profissional e a paciente. A mulher não tocava este assunto porque era um tema tabu, e nós médicos, muito menos, porque significava invadir um terreno perigoso, com a possibilidade de ser mal interpretado. Além do mais que adiantava perguntar sobre a vida sexual da paciente se você não sabe o que fazer com a resposta. Ainda hoje acho graça quando vejo em algum prontuário de certos hospitais universitários a seguinte pergunta: "A senhora tem orgasmo?" Se a mulher responde "sim" tudo bem, e se ela responder "não". O que diabos o profissional vai fazer

- Título dado pelo entrevistado. 
com esta resposta? Normalmente ele não teve uma formação em terapia sexual em sua faculdade e, quando muito, assistiu uma aulinha em um congresso qualquer.

O que cada médico faz - e eu me refiro àqueles que não têm nenhuma formação em terapia sexual - é se meter à dar conselho baseado em sua própria experiência de vida. Isto na maioria dos casos não funciona. Outros se transformam em um grande ouvido. Ouvem toda a história, às vezes uma enorme verborréia com digressões de todos os tipos e apela para que a mulher tenha paciência, que isto vai se resolver com o tempo. Ouvir é muito bom já alivia a paciente porque encontrou a quem dividir seu problema, mas, na maioria das vezes, também não resolve o caso.

É engraçado. Quando o indivíduo quer ser ginecologista recebe uma orientação específica, "rala" numa residência, atende pacientes sobre supervisão direta. $\mathrm{O}$ mesmo se diga de qualquer especialidade médica. Mas para fazer sexologia as pessoas acham que não se necessita nada disso. É realmente assombroso...

É bom esclarecer meu caro Paulo que isto se aplica também aos psicólogos. Nas faculdades de psicologia usualmente não existe um curso de terapia sexual. Existem informações - acredito que boas - sobre as diferentes terapias, mas a "terapia sexual" hoje tem uma formulação absolutamente peculiar. Não basta ser behaviorista ou psicanalista, por exemplo, para aplicar estes conhecimentos aos distúrbios sexuais, como se o comportamento sexual fosse um comportamento como outro qualquer. Eu acredito que grande parte dos insucessos dos tratamentos sexuais decorre deste tipo de aplicação. E eu vou parar por aqui porque isto vai dar uma confusão danada e nesta altura da vida eu não tenho tempo de estar discutindo e comprovando este ponto de vista. Uma coisa é evidente não basta ser médico ou psicólogo para saber fazer terapia sexual. É preciso ter uma formação apropriada e usar os conhecimentos médicos e psicológicos como um material inicial para uma longa jornada de formação em Sexologia Clínica. Devo acrescentar que Terapia sexual moderna não é exclusivamente psicoterapia. É psicoterapia mais farmacoterapia. Uma ajuda a outra, uma complementa a outra, como o corpo complementa a alma. 
Você me pergunta como é que um ginecologista se tornou sexólogo? Deixe-me primeiro fazer umas considerações. É preciso dar uma definição operacional do que significa "sexólogo". Sexólogo é uma palavra esquizofrênica. Pode ser muita coisa e muita gente se intitula sexólogo.

O fato é que em sexologia podemos distinguir três grandes ramos: a educação sexual, a pesquisa sexológica e a sexologia clinica. Educadores sexuais são sexólogos e temos muita gente bastante competente nesta área. A pesquisa sexológica pode ser subdividida em pesquisa médico sexual e pesquisa sócio-cultural. Nesta se investiga o comportamento sexual das pessoas de uma determinada cultura, região geográfica ou grupamento humano. Um exemplo disso são os trabalhos de Kinsey, Hite e outros. No Brasil também temos gente competente nesta área. São sexólogos. Finalmente sexologia clínica está voltada ao tratamento das inadequações sexuais. É, portanto terapêutica e também temos muitos terapeutas sexuais no Brasil. Como você pode constatar, sexólogo é uma palavra ruim porque quer dizer muita coisa e por isso confunde as pessoas. Bom, voltemos ao nosso assunto.

Muito cedo, lá nos meados da década de 70, quando chegou entre nós os reflexos da chamada "revolução sexual", as mulheres começaram a falar no consultório suas queixas sexuais. No começo eram queixas "mascaradas” depois explícitas. Eu tinha uma grande clientela de gínecoobstetricia nesta altura, e comecei a ficar inquieto, porque não sabia como enfrentar este problema e queria ajudar minhas clientes. Na época eu morava em Brasília e entre minhas pacientes eu tinha a senhora do embaixador americano. Era uma pessoa muito inteligente, muito aberta a discutir qualquer tipo de assunto e com uma bela formação universitária em sociologia.Como eu tinha curso de antropologia e era titular desta disciplina, ficamos muito amigos e conversávamos muito sobres as mudanças culturais que estavam ocorrendo no mundo e, naturalmente, sobre as dificuldades que eu estava encontrando no consultório, pára me adequar a essas mudanças.

Certa ocasião ela me disse que iria me dar um presente. Uns vinte dias depois me chegou com dois livros. Um, publicado nos anos 50, e outro mais recente, ambos dos mesmos autores, um tal de Williams Masters e Virginia Johnson e ambos com uma dedicatória para mim. Devorei os livros e aí começou realmente a minha busca por uma formação sexológica. Alguns anos depois eu conheci pessoalmente o casal Masters e Johnson e agradeci as dedicatórias. Eles sorriram e 
fizeram uma cara de que não sabiam o que eu estava dizendo. Eu ainda hoje não sei se isto se deveu ao meu péssimo inglês ou ao fato deles darem tantos e tantos autógrafos. E eu, naturalmente, estava entre os muitos insignificantes do mundo.

Cedo, muito cedo, eu cheguei a conclusão de que não sabia nada de psicoterapia. Começou então minha longa peregrinação. Li Freud - a coleção inteira- publicada pela editora Imago, sob a supervisão de Jayme Salomão. Digeri e ruminei os 20 e tantos volumes e, se isto não bastasse li o interessante livro de Ernest Jones sobre a Vida e Obra de Sigmund Freud. Nunca fui psicanalizado, mas fiquei bem ilustrado em psicanálise, aliás (me perdoem os psicanalistas) o suficiente para não querer ser psicanalizado.

Passei por cima de Jung, mas me encantei com Adler. Minha primeira esposa Mabel estava fazendo um curso de Psicologia na Universidade de Brasília. Ela já era formada em Filosofia e História. O fato é que ela assistia à aula e nós dois estudávamos juntos em casa. Assim eu fiz um curso não regular de Psicologia. Nunca me interessei em cursar a Faculdade de Psicologia, mas fiz o curso completo e parece que bem aplicado. Vou lhe contar um fato que corrobora isto.

Certa ocasião eu estava atendendo uma cliente quando recebi um telefonema de uma Coordenadora da pós-graduação de Psicologia de uma universidade de São Paulo. Era um convite para eu ir dar duas aulas no curso de doutorado. Eu aceitei e ela ficou de me mandar os temas. Eu estava certo de que se tratava de alguma coisa de sexologia e deixei para preparar as aulas quando estivesse mais perto. Confesso que me esqueci totalmente do assunto.

Um mês ou um mês e meio depois, minha secretária me chamou atenção de que eu deveria ir a São Paulo, na semana seguinte e que a Professoara tinha me mandado o tema. Fiquei pálido. Os títulos eram: “Aplicação dos Princípios do Reforçamento Operante ao Comportamento Humano". Jesus, confesso que tive vontade de mandar dizer que tinha tido um infarto e teria tido o tal do infarto mesmo, se Mabel não tivesse me mostrado que no livro do Ferster - um comportamentalista clássico - tinha alguma coisa como umas 50 páginas versando exatamente sobre o miserável assunto. Passei 4 dias inteiros - de 6 da manhã a meia noite - estudando o tema porque uma coisa ia puxando outra. As palestras ficarão prontinhas pouco tempo antes de embarcar para São Paulo. 
Fui recebido com todas as honras - mais do que eu merecia - e dei minhas aulas. Ao término fui muito aplaudido, respondi todas as perguntas e a Coordenadora ao encerrar minha participação disse textualmente "Eu quero agradecer profundamente as magníficas aulas com que nos brindou o nosso colega psicólogo Ricardo Cavalcanti”. Tive vergonha de dizer que eu não era psicólogo. (Se ela ler esta entrevista, meu caro Paulo, estou desmascarado)

Ora, Canela, se a mulher que era especialista, mestra, doutora, pós doutora, titular de Psicologia, e formadora de doutores em Psicologia me disse que eu era psicólogo quem pode me contestar que, embora sem diploma acadêmico, eu não seja um psicólogo... pelo menos um psicomédico. Anos depois eu comentei o fato com o Araguari e ele me disse que eu tinha "cara de pau". "Mas Arágua o que é que eu vou fazer se a mulher disse que eu sou psicólogo". Claro que não vou por uma placa no meu consultório nem oferecer serviços de psicologia. Ao que Jean Claude Nahoun acrescentou: "Além de "cara de pau" você seria um fdp curandeiro". Velhos e queridos amigos. Deus lhes dê o céu inteiro.

O fato é que para suprir minhas limitações na psicologia reuni um grupo de médicos, psicólogos e antropólogos, em Brasília, e fundamos o CESEX (Centro de Sexologia de Brasilia. A fundação foi exatamente em 74, mas só foi legalmente instituído em 9 de setembro de 1980.

Todos eram professores universitários e nos reuníamos semanalmente, aos sábados, para falar de sexologia clínica. Era sempre designado um participante para discorrer sobre um assunto que poderia ser de medicina sexual, antropologia ou psicologia. O restante do grupo fazia perguntas, discordava, acrescentava, enfim discutia o tema. Todos estudavam e já vinham preparados. Ao término da reunião um relator fazia um resumo e distribuía com todos os participantes. Assim pouco a pouco, todos nós, médicos, antropólogos e psicólogos íamos adquirindo os mesmos conhecimentos e uma mesma linguagem Todas as escolas psicoterápicas foram discutidas, nos metemos a estudar os aspectos culturais da sexualidade nos diferentes povos, todos os conhecimentos biológicos de anatomia, fisiologia e patologia ligadas ao desempenho sexual foram abordados.

Depois que adquirimos uma boa base teórica os médicos e os psicólogos do grupo decidiram investir em sexologia clínica. O referencial teórico era comportamental com muita influência das 
teorias existencialistas, embora fôssemos bastante ecléticos em relação a aplicação de técnicas formuladas por outros sistemas psicoterápicos.

O CESEX abriu um consultório para atendimento gratuito da população e nele testamos e retestamos procedimentos terapêuticos. Discutíamos os casos clínicos e, aos poucos fomos adquirindo a habilidade no tratamento das inadequações sexuais. Em 1981, portanto 20 anos, eu e a Mabel publicamos o livro Tratamento clínico das Inadequações sexuais (Ed. Roca) fruto de toda esta experiência. Já está na terceira edição (2006) e já começo a pensar numa quarta mais atualizada ainda.

A partir de 1984 passamos a oferecer, sem interrupção, 2 vezes por ano, cursos de preparação em terapia sexual, para médicos e psicólogos. Foi o primeiro curso no Brasil que se propunha a esta formação e o segundo da America Latina. Não fazemos muita divulgação deste curso, mas ele continua vivo porque são os colegas que fazem o curso que se encarregam de divulgá-lo.

Em 1983 foi criada, na FEBRASGO (Federação Brasileira de Ginecologia e Obstetrícia), a Comissão Nacional de Sexologia. Fui convocado para presidi-la e logo convidei Jean Claude Nahoun, Aulus Plautus de Souza, Nelson Vitielo, Araguari Chalar Silva, Joaquim Lopes, Maria Tereza Maldonado, José Maria Sales, Henrique Augusto Moreira Lima, José Granado Neiva e Rosiris Andrade. Em 1986 esta Comissão foi modificada e acrescida de Mabel Cavalcanti, Maria do Carmo Silva, Maurício Viggiano, Paulo Canela e Heitor Hentschel.

Quem se propuser a escrever a história da Sexologia Brasileira verá que a Comissão Nacional teve uma importância muito grande para a Sexologia de nosso país. Certa ocasião Araguari escreveu que a sexologia em nossa terra pode ser classificada em duas fases: antes e depois da Comissão Nacional de Sexologia.

O fato é que com a Comissão Nacional de Sexologia começaram os "Encontros Nacionais" de Sexologia. Do Primeiro Encontro nasceu o livro Sexologia 1, publicação feita por uma editora criada por Paulo Canela e Nelson Vitiello. A Editora, que se chamava FEMINA, nasceu cheia de esperanças de publicar livros futuros, estando, em sonhos, fadada a ser uma concorrente certa e perigosa da Editora Globo. Ela nunca passou daquele primeiro livro, que, aliás, foi um sucesso 
de vendas e um fracasso de distribuição. A editora FEMINA murchou, morreu de esperança, como morrem os sonhos dos loucos, dos bêbados e dos poetas.

Neste passeio pela minha vida, meu caro Paulo não posso me esquecer da insistência de Nelson Vitiello e de Paulo Canela para criar uma sociedade de sexologia que abrangesse todos os que, de alguma forma fazem educação, pesquisa ou sexologia clínica. Uma sociedade multidisciplinar.

Nunca vou me esquecer como foi fundada a Sociedade Brasileira de Sexualidade Humana. - a SBRASH. Na verdade é impossível apagar da memória aquele fim de tarde de junho. Fazia um frio danado. Eu, Paulo Canela e Nelson Vitiello estávamos no "escritório" do Nelson, que era um bar de segunda categoria, na esquina defronte do Instituto de Biologia de São Paulo. Tramávamos a criação da SBRASH, mas eu resistia em acabar com a Comissão Nacional de Sexologia da FEBRASGO. Canela e Vitiello propunham uma coisa no lugar da outra, e eu defendia a idéia das duas conviverem juntas. Quando os dois já estavam meio bêbados ficou acertada a convivência pacífica das duas entidades. Nasceu a SBRASH, entre goles de pura aguardente e coxinhas de rã.

Tramamos uma possível diretoria. Queriam que eu fosse o Presidente. Claro que eu não aceitei. Era presidência demais para um só indivíduo. No primeiro encontro que foi em Curitiba a chapa eleita foi Presidente Jean Claude Nahoun, Vice-Presidente Araguari Chalar Silva e (sem poder me livrar) Secretário Geral Ricardo Cavalcanti.

Nós éramos realmente três mosqueteiros: Paulo Canela, Nelson Vitiello e eu. Fizemos muitas coisas juntas, nos divertimos muito, gargalhamos por este Brasil afora. Creio que se lembra de nossa peregrinação, pelos Estados, ministrando um curso sobre adolescência, mais tarde convertido no livro Adolescência Hoje. Velhos amigos, velhos tempos. Quanta saudade.

Está bom de tanta entrevista Paulo. Há muita coisa que poderia ainda falar, mas fica para outra oportunidade. 